\title{
УДК 528.004
}

\section{ОРГАНИЗАЦИЯ СИСТЕМЫ ГЕОИНФОРМАЦИОННОГО МОНИТОРИНГА СОСТОЯНИЯ ЗЕМЕЛЬНЫХ РЕСУРСОВ ПРИБРЕЖНОЙ ЗОНЫ НОВОСИБИРСКОГО ВОДОХРАНИЛИЩА}

\author{
Карпик Александр Петрович',
} rektorat@ssga.ru Аврунев Евгений Ильич',
avrynev_ei@ngs.ru

\author{
Добротворская Надежда Ивановна', \\ dobrotvorskaya@mail.ru
}

\author{
Дубровский Алексей Викторович', \\ avd5@mail.ru
}

\author{
Малыгина Олеся Игоревна', \\ 131379@mail.ru

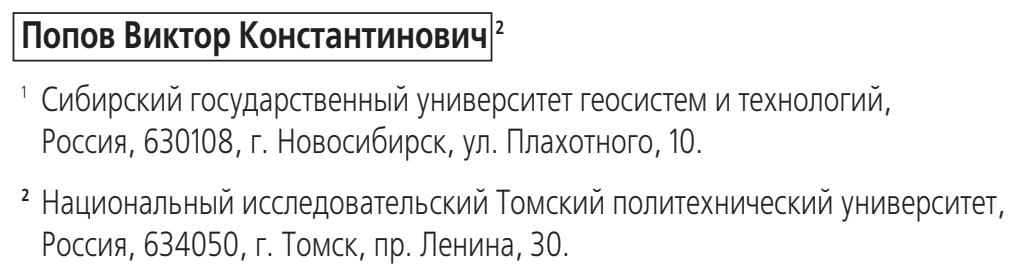

Актуальность исследования обоснована тем, что современная организация объектов инфраструктуры промышленных и хозяйственных комплексов должна быть безопасна, экологически и экономически эффективна. Поставлена проблема организации системы рационального использования и контроля состояния водохранилищ с применением геотехнологий и систем дистанционного зондирования Земли. В качестве объекта исследования рассматривается территория Новосибирского водохранилища - техногенного природно-территориального комплекса. На исследуемой территории водохранилища отмечается ухудшение экологической ситуации в результате прогрессирования ветро-волновой эрозии береговой линии и интенсивного смыва в воду почвы, растений, деревьев, химических сельскохозяйственных удобрений и т. д. По данным дистанционного зондирования Земли определены скорости эрозии почв на всем протяжении береговой линии водохранилища. На основании проведенных почвенных обследований и типизации почв составлена прогнозная модель разрушения береговой линии. Установлены участки геодинамического мониторинга и определена периодичность наблюдений. Сделаны выводы о необходимости проведения берегоукрепительных работ, а также более широкого вовлечения территории водохранилища в рекреационное использование. Цель: разработать систему геоинформационного мониторинга состояния земельных ресурсов прибрежной зоны водохранилища на примере территории Новосибирского водохранилища.

объекты: земельные ресурсы прибрежной территории Новосибирского водохранилища.

Методы. При решении поставленных задач использовались как общие методы исследования (системный анализ, синтез, наблюдение, сравнение, измерение, обобщение), так и специальные методы исследования (мониторинг состояния земель и окружающей природной среды с использованием данных дистанционного зондирования Земли, методы цифровой картографии и геоинформационного анализа и моделирования).

Результаты. Разработана технологическая схема организации системы геоинформационного мониторинга техногенного природно-территориального комплекса - водохранилища. Построена прогнозная градиентная модель скоростей смещения береговой линии водохранилища. На основании анализа данной модели определен перечень объектов недвижимости, которые будут разрушены в результате прогрессирования ветро-волновой эрозии.

\section{Ключевые слова:}

Спутниковые методы мониторинга, техногенные природно-территориальные комплексы, земельные ресурсы, беспилотные летательные аппараты, цифровая экономика, водные объекты.

\section{Введение}

В настоящее время перед человечеством стоит ряд глобальных проблем, из которых можно выделить пять наиболее актуальных, таких как: социальная, экологическая, продовольственная, энергетическая, водная. Решение первых четырех невозможно без решения водной проблемы. Поскольку современное состояние водных объектов ухудшается с каждым годом, и данная ситуация вселяет опасение за будущее человечества, ученые многих стран мира считают главной проблему обеспечения водой населения и хозяйства. На нашей планете создание искусственных водохранилищ привело к изменению природных свойств территории на площади более 700 тыс. км². При этом инфраструктурные изменения коснулись территории более 1,5 млн км ${ }^{2}$ [1]. В первую очередь это связано с интенсивным строительством объектов 
недвижимости на прилегающих к водохранилищам территориях и миграцией населения.

Также актуальность темы исследования подчеркивается и тем фактом, что в средствах массовой информации в последнее время возросла критика водохозяйственных мероприятий, связанных с созданием и эксплуатацией водохранилищ. Результаты такого антропогенного вмешательства в естественные водные системы вызывает существенные экологические изменения на территории водосборной площади. Часто строительство водохранилищ приводит к снижению качества воды в результате попадания загрязняющих веществ. Загрязнителями могут выступать как сельскохозяйственные и промышленные стоки, так и естественные загрязнители воды, образующиеся в результате разрушения береговой линии. Все перечисленные негативные факторы в совокупности с затоплением огромных площадей при строительстве водохранилищ приводят к сокращению земельных ресурсов и ухудшению их качества.

Особенно остро эти проблемы проявляются на водохранилищах равнинного типа, к которым относится Новосибирское водохранилище, представленное на рис. 1 [1-3].

В качестве одного из решений перечисленных выше проблем специалистами- экологами предлагается снижение подпорных отметок или же в некоторых случаях даже полный спуск водохранилищ [2]. Подобные сценарии являются крайне нежелательными, так как сложившаяся вокруг водохранилищ инфраструктура, а также сформированные объекты недвижимости могут существенно изменить свои характеристики, в том числе и кадастровую стоимость. В связи с этим актуальным является решение задачи организации системы мониторинга состояния земельных ресурсов прибрежной зоны водохранилищ с использованием геотехнологий и беспилотных аэрофотосъемочных систем. В результате будут определены участки береговой линии, подверженные ветро-волновой эрозии, а также составлена модель дальнейшего прогрессирования негативных эрозионных процессов.
Использование земельных ресурсов для ведения хозяйственной деятельности должно быть не только экономически эффективным, но и экологически целесообразным. При современных уровнях техногенной трансформации естественных ландшафтов и перестройке природных систем в результате промышленного и хозяйственного освоения территорий уже невозможно найти отдельный земельный участок, не испытывающий антропогенного воздействия. В этих условиях актуальным является разработка экологически-ориентированного рационального подхода $\kappa$ природопользованию на землях, занятых крупными промышленно-хозяйственными образованиями - техногенными природно-территориальными комплексами (ТПТК).

Водохранилища являются сложными гидротехническими сооружениями, которые кроме своих непосредственных функций, могут решать еще ряд задач, связанных с обеспечением населения рекреационными ресурсами. Во всем мире наблюдается рост популярности национальных парков, природных зон отдыха [4]. Для создания системы управления рекреационной зоной должна быть разработана пространственная цифровая экономическая модель развития. При этом методы точного мониторинга состояния территории с использованием геотехнологий должны сочетаться с методами экономического моделирования и прогнозирования. Как и любой ТПТК рекреационные зоны водохранилищ должны приносить экономический доход от хозяйственного использования. При правильной организации системы землепользования возможно получение постоянной устойчивой прибыли как эксплуатирующими территорию субъектами частного бизнеса, так и местными и региональными властями [5-7].

\section{Цели исследования}

В результате проведения исследований разработана система геоинформационного мониторинга состояния земельных ресурсов прибрежной зоны водохранилища на примере территории Новосибирского водохранилища.

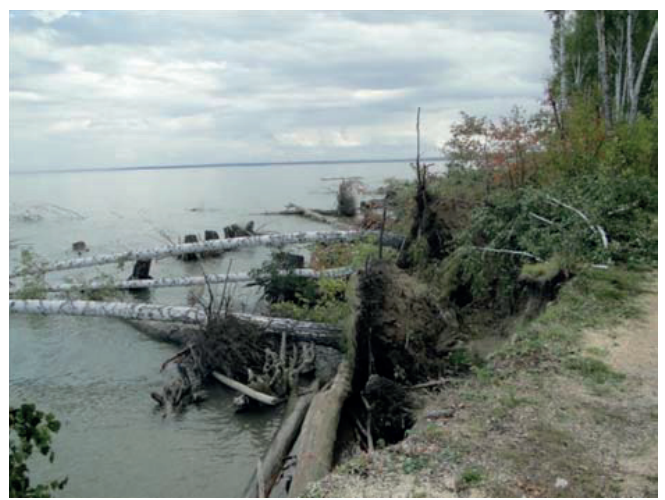

$a / a$

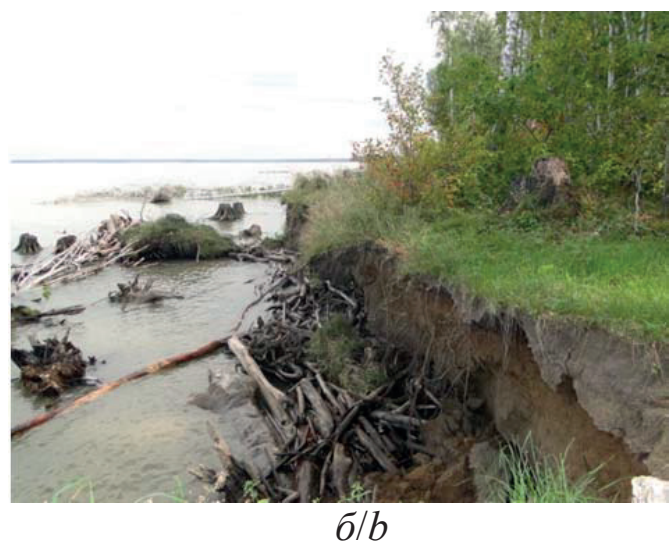

$\sigma / b$

Pис. 1. Примеры разрушения берегов Новосибирского водохранилища: а) село Завьялово; б) село Сосновка

Fig. 1. Examples of destruction of the Novosibirsk water basin shore line as the result of wind-and-wave soil erosion: a) near the village Zavya lovo; $b$ ) near the village Sosnovka 


\section{Методы исследования}

В соответствии с концепцией развития отрасли геодезии и картографии до 2020 г. [8] в интересах совершенствования картографо-геодезического производства и модернизации системы картографического обеспечения РФ особо остро стоит проблема разработки современных методов актуализации пространственных данных картографо-геодезического фонда и разрабатываемой инфраструктуры пространственных данных. Одним из путей решения данной проблемы является усовершенствование технологий обновления картографических материалов с использованием данных космических съемок. Осуществляемый в РФ государственный топографический мониторинг состоит из взаимосвязанных информационно-технологических сегментов: географического, космического, картографического, спутниково-навигационного и геоинформационного [9].

Без актуальной и достоверной информации о земельных ресурсах невозможно эффективное управление, контроль, надзор и координация деятельности различных министерств и ведомств. С помощью космических снимков можно выполнять работы по созданию генеральных планов населенных пунктов, разработке проектной документации, планированию мест размещения инвестиционных площадок, выявлению незаконного строительства, созданию схем территориального планирования и многое другое. При этом современные спутниковые системы дистанционного зондирования могут обеспечить съемку поверхности Земли с пространственным разрешением до 0,23 м, а аэрофотосъемочные комплексы - 0,1 м и крупнее. Эти пределы точности удовлетворяют

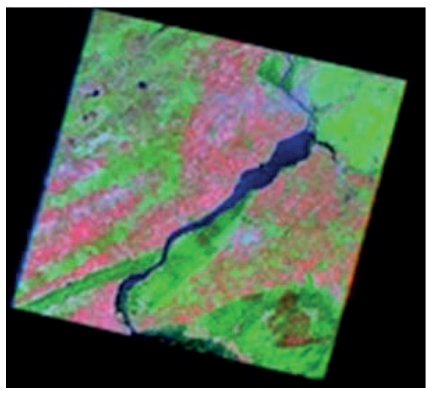

$a / a$

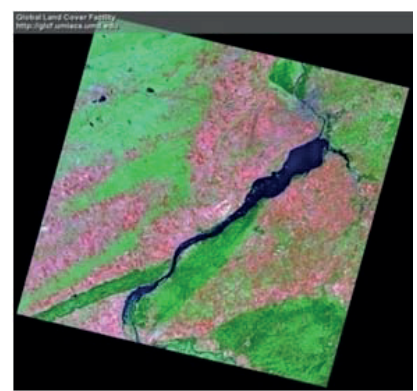

$B / c$ практически всем видам работ, которые может проводить специалист по управлению земельными ресурсами. Определение границ территориальных зон, границ муниципальных образований, памятников природы, объектов регистрации прав - это далеко не полный список работ, которые могут быть выполнены с использованием данных дистанционного зондирования Земли (ДДЗЗ).

Современные системы мониторинга территории, системы раннего предупреждения и ликвидации последствий чрезвычайных ситуаций, гидрометеорологические службы являются активными потребителями информационного ресурса, который предоставляют ДДЗ3. Кроме того, в настоящее время существуют примеры, когда спутниковая съемочная система изначально проектируется и разрабатывается для решения конкретных задач, связанных с мониторингом чрезвычайных ситуаций и оперативного обеспечения заинтересованных служб и ведомств актуальными ДДЗ3. Подобной системой является российская разработка космического аппарата «Канопус-М» [10].

Территория водохранилищ является одним из наиболее интересных и важных с позиции геомониторинга объектов наблюдений. В первую очередь это обосновано стратегическими задачами по обеспечению водными ресурсами населения. Также интерес представляет и научное изучение состояния ТПТК и динамики его поведения как техногенного объекта. При проектировании водохранилищ одним из обязательных параметров является установление проектного срока эксплуатации. Например, для Новосибирского водохранилища проектный срок эксплуатации составляет 450 лет. Однако при выполнении расчетов были заложены минималь-

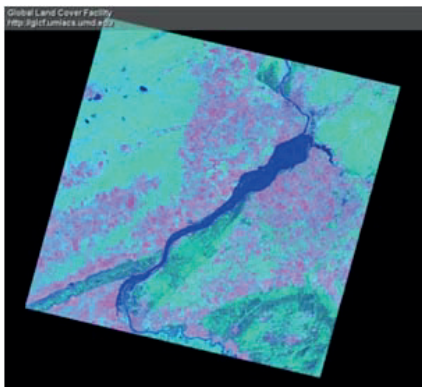

$\sigma / b$

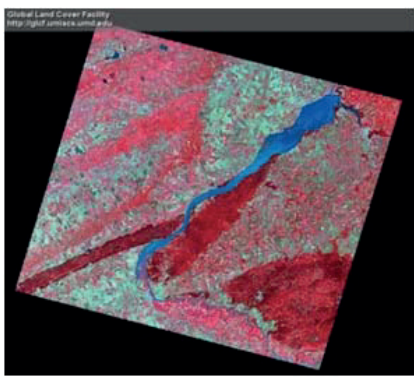

$2 / d$

Pис. 2. Исходные ДДЗЗ на территорию Новосибирского водохранилища.Съемка: а) 2016 г.; б) 2009 г.; в) 1999 г.; г) 1989 г.

Fig. 2. Initial Earth remote sensing data of the Novosibirsk water basin in: a) 2016; b) 2009; c) 1999; d) 1989 
ные скорости разрушения береговой линии в результате ветро-волновой эрозии. Фактическая скорость разрушения берегов превышает проектные расчеты в 10 раз. В результате темпы заиления водохранилища также превышают проектные значения. Поэтому конечный срок эксплуатации водохранилища может уменьшиться до 250 лет.

При проведении исследования состояния береговой линии Новосибирского водохранилища, анализа интенсивности и локализации процессов берегоразрушения были использованы разновременные данные дистанционного зондирования Земли, материалы полевых наблюдений, а также почвенные карты территории района работ. Часть данных была получена при поддержке группы компаний «СКАНЭКС» в рамках договора о научно-техническом сотрудничестве, рис. 2.

Для автоматической векторизации разновременных контуров Новосибирского водохранилища по космическим снимкам растровое изображение было разбито на классы с помощью неуправляемой классификации Isodata. Использование этого алгоритма осуществляется посредством диалога Isodata classification в программном обеспечении Image Procesion [11].

Оперативный мониторинг состояния береговой линии водохранилища осуществляется с использованием технологий беспилотных авиасистем. Полученные снимки высокого разрешения применяются для решения следующих задач:
- оперативный мониторинг состояния территории; - контроль скорости разрушения береговой линии;

- создание и обновление карт и планов;

- решение задач проектирования систем рационального природопользования (в том числе и разработка схем рекреационного использования земельных ресурсов);

- проведение мероприятий по инвентаризации;

- ведение кадастров.

В качестве съёмочного оборудования целесообразно использовать цифровые фотографические камеры с полноразмерными или ASP-C матрицами, обеспечивающие получение снимков высокого качества. Также рекомендовано наличие на борту ГНСС-приемников, обеспечивающих сантиметровую точность выполнения спутникового позиционирования. В качестве примера БПЛА, оснащённых необходимым для съёмки оборудованием, можно привести Геоскан 101 и Геоскан 201 [12]. В случае отсутствия спутниковой аппаратуры сантиметровой точности требуется создание планововысотного съёмочного обоснования геодезическими методами. Фотограмметрическая обработка материалов аэрофотосъёмки выполняется с использованием цифровых фотограмметрических станций PHOTOMOD или аналогичного программного обеспечения: Agisoft PhotoScan, Trimble Inpho UASMaster.

Большинство современных техногенных природно-территориальных комплексов изменяются

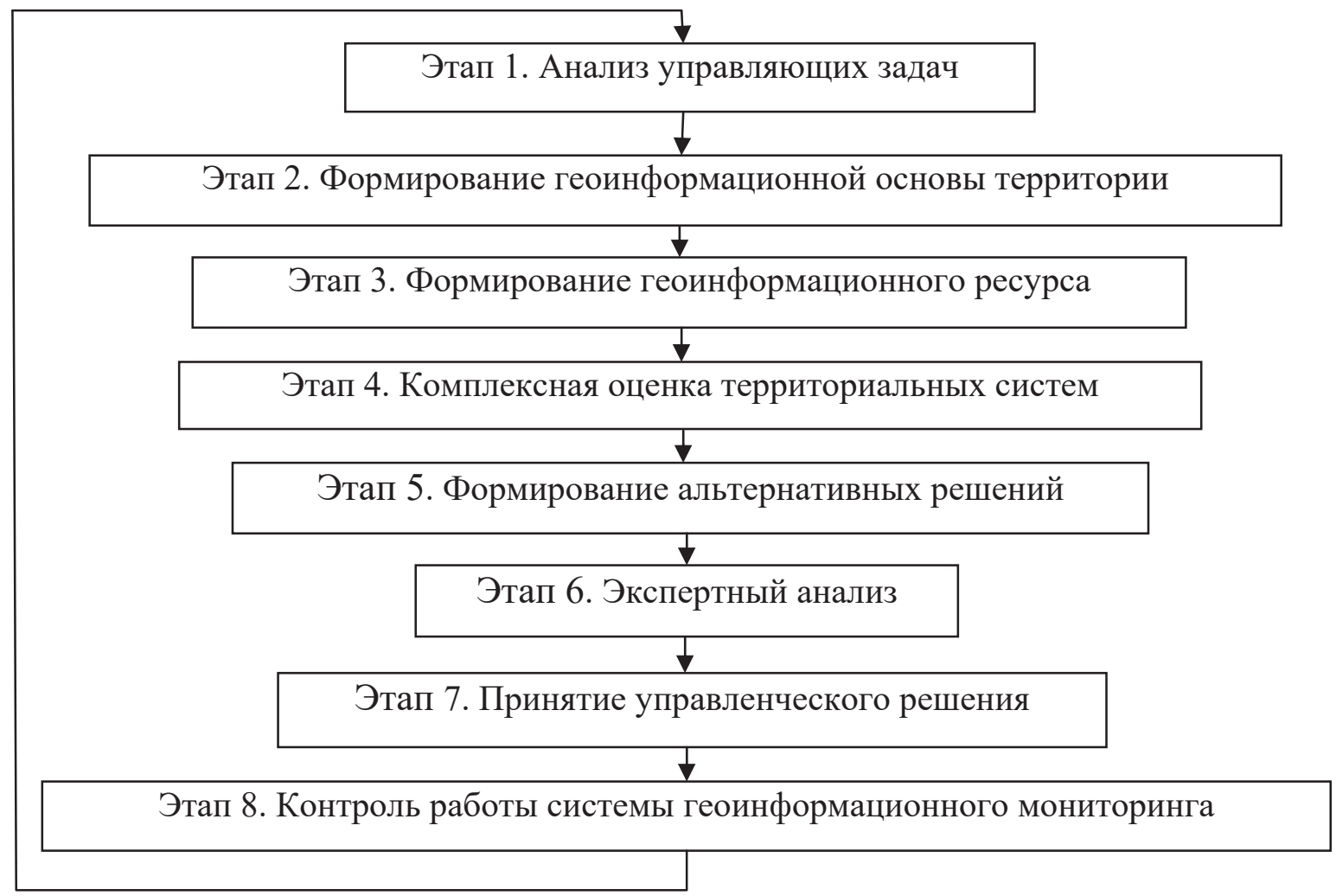

Рис. 3. Технологическая схема геоинформационного мониторинга ТПТК

Fig. 3. Technological scheme of geoinformational monitoring of TNTC 
во времени, приобретают новые качества. При этом техногенный характер возникновения объекта предполагает наличие проектных показателей нормального состояния и функционирования ТПТК. В ряде случаев подобного рода показатели определены в нормативно-правовых актах, санитарных нормах и правилах, показателях предельно-допустимых концентраций и т. п. Мониторинг состояния ТПТК выполняется на различных уровнях, при этом в современном понимании мониторинг не ограничивается определением происходящих изменений. Для создания прогнозных моделей формируются разновременные базы данных, которые содержат комплекс разнородной информации о территории. ДДЗЗ и векторная геоинформация составляют основу для осуществления геоинформационного мониторинга.

Предлагаемые технологические решения позволили сформировать технологическую схему геоинформационного мониторинга территории ТПТК, которая представлена на рис. $3[7,13]$.

Разработанная технологическая схема геоинформационного мониторинга ТПТК ориентирована на применение современных геотехнологий и реализует принципы рационального, экологически-ориентированного землепользования и достижения устойчивого развития территорий с соблюдением норм промышленной безопасности $[7,14]$.
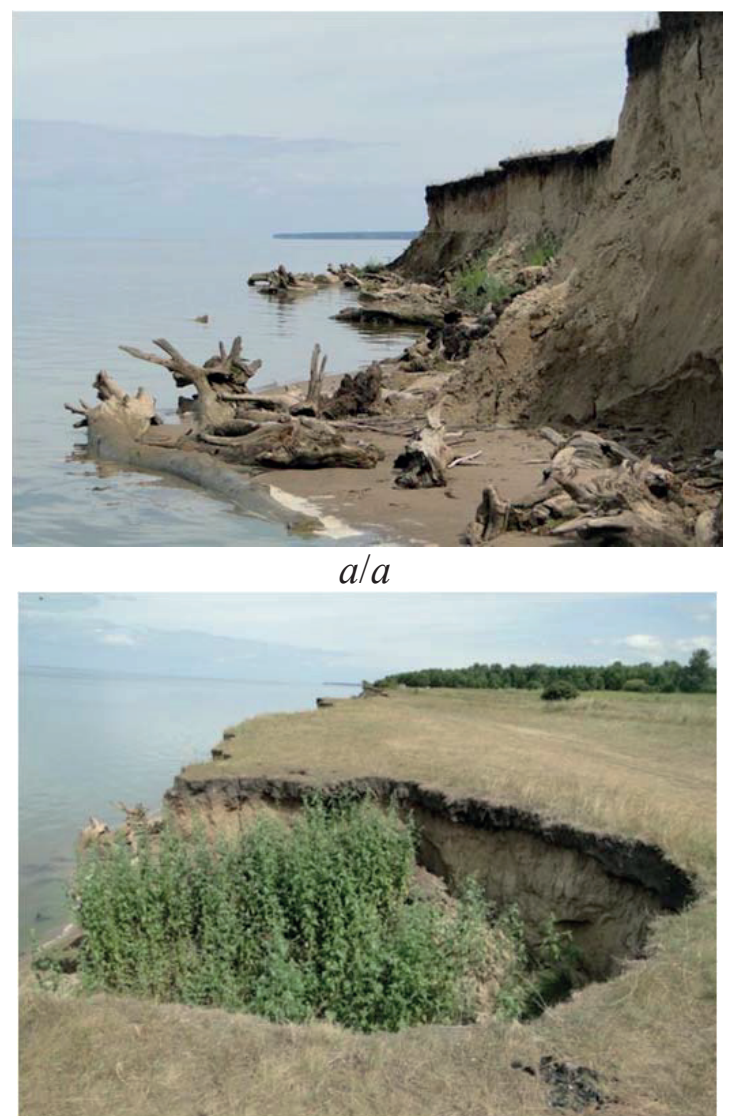

$B / c$

\section{Результаты исследования}

Водохранилища представляют собой ТПТК систему, состоящую из природных и искусственных объектов, взаимодействующих на различных структурных уровнях и оказывающих влияние друг на друга. На территории Новосибирского водохранилища ежегодно проводится комплекс полевых работ, связанных с определением участков береговой линии, разрушаемых в результате прогрессирования ветро-волновой эрозии (рис. 4). Действие негативных процессов берегоразрушения установлено на 70 \% территории водохранилища.

Однако вместе с этим в период с 2014-2016 гг. на некоторых участках береговой линии протяженностью около 10 км были проведены берегоукрепительные работы, показанные на рис. 5.

В результате анализа разновременных ДДЗ3 были получены карты положения береговой линии водохранилища на различные даты с момента его создания (рис. 6). Установлено также, что на некоторых участках береговая линия смещалась со скоростью до 5 м в год.

По полученным в результате анализа контурам водохранилища было определено разрушение берегов за 40 лет и выделены места наибольшего разрушения. Также на основании полученных данных разработан план мероприятий по укреплению

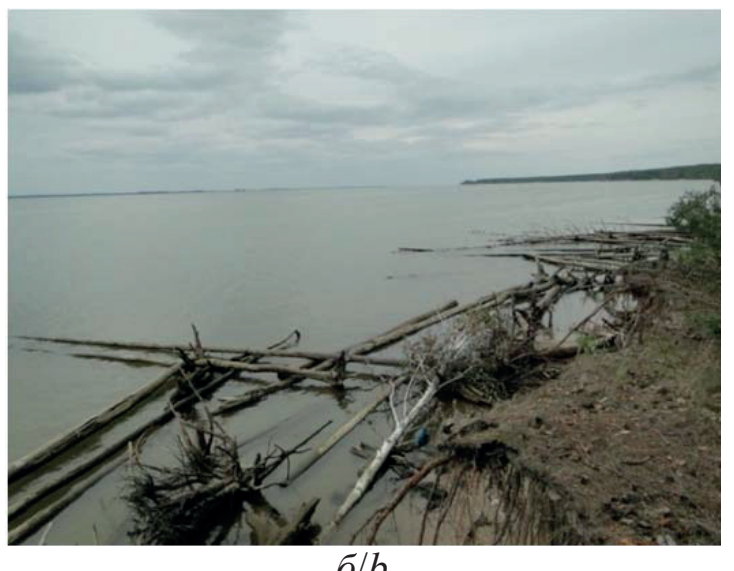

$\sigma / b$

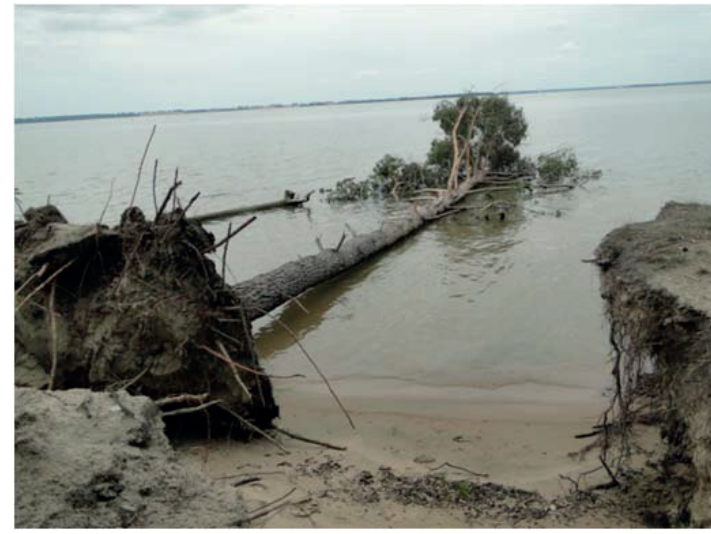

$2 / d$

Puс.4. Примеры разрушения берегов Новосибирского водохранилища

Fig. 4. Examples of shore line destruction of the Novosibirsk water basin 

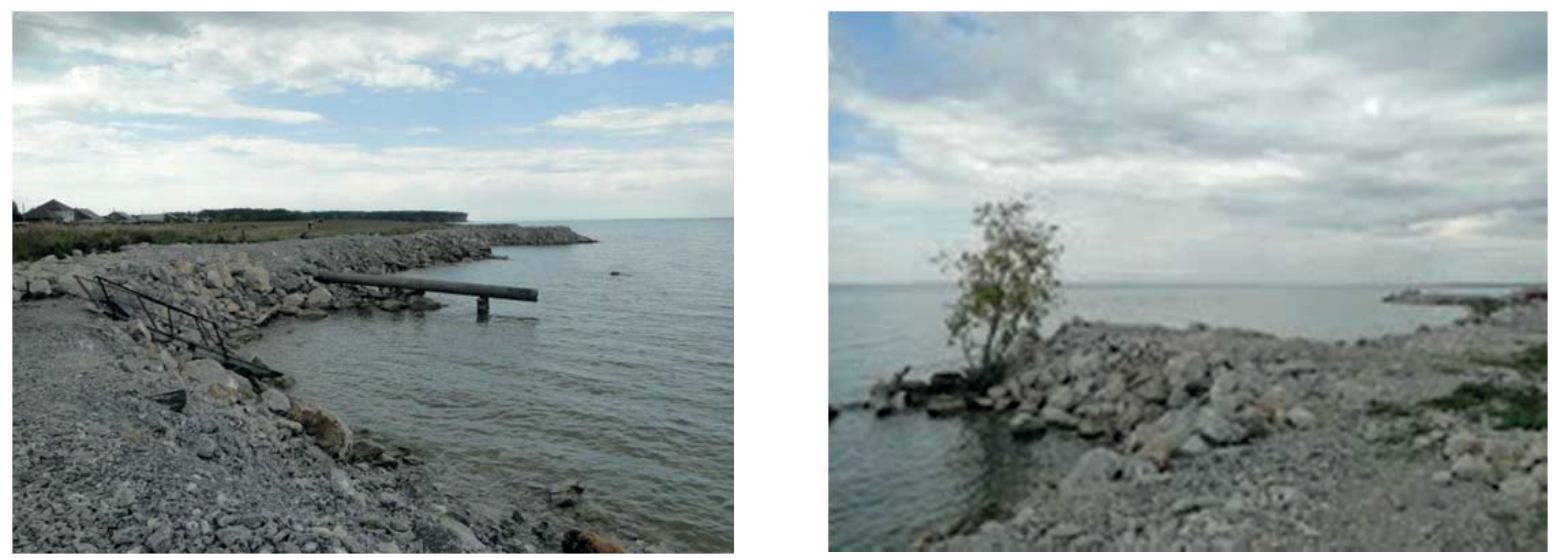

Рис. 5. Примеры берегоукрепления Новосибирского водохранилища

Fig. 5. Example of shore line stabilization, the Novosibirsk water basin

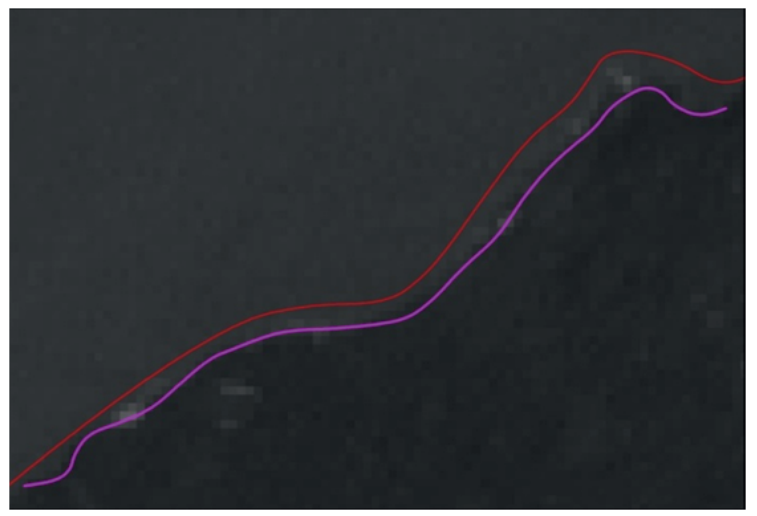

контур водохранилища в 1979 году контур водохранилища в 1989 году $a / a$

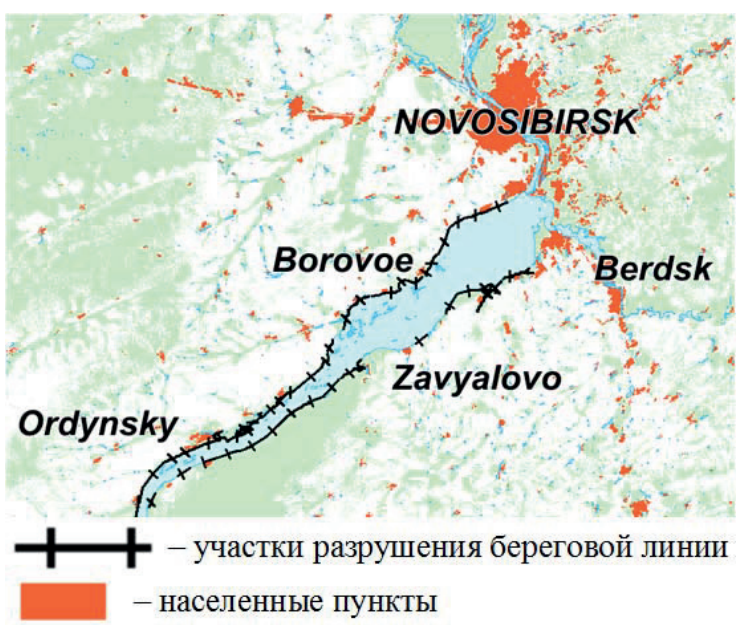

$\sigma / b$

Pис. 6. Результат анализа ДДЗ3: а) Сравнение положения двух разновременных контуров береговой линии водохранилища вблизи села Завьялово; б) Участки береговой линии Новосибирского водохранилища, подверженные разрушению в результате прогрессирования ветро-волновой эрозии

Fig. 6. Result of remote sensing data analysis of the Novosibirsk water basin territory: a) example of shore line shift as the result of shore line reproduction near the village Zavyalovo; b) shore line parts of the Novosibirsk water basin, subjected to destruction

берегов. По типу разрушения береговой линии предложено дополнить существующую классификацию В.Т. Трофимова [15], которая включала умеренно-опасный, опасный, особо опасный типы разрушения, дополнительным типом - катастрофическим (таблица).

На рис. 7 представлена градиентная модель смещения береговой линии за период с 1979 по 2016 гг.

На рис. 7 цифрами обозначены участки, которые в первую очередь нуждаются в проведении берегоукрепительных работ и организации системы геодезического мониторинга. Для создания прогнозной модели разрушения береговой линии водохранилища были проведены почвенные исследования, по результатам которых получены данные о наиболее подверженных размыву участках. На рис. 8 представлен фрагмент почвенной карты.
Таблища. Классификационные характеристики разрушения береговой линии Новосибирского водохранилища

Table. Classificatory characteristics of the Novosibirsk water basin shore line deformation

\begin{tabular}{|c|c|c|c|c|}
\hline \multirow[t]{2}{*}{$\begin{array}{c}\text { Тип разрушения } \\
\text { береговой линии } \\
\text { Shore line deformation type }\end{array}$} & \multirow{2}{*}{ 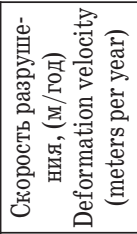 } & \multicolumn{2}{|c|}{$\begin{array}{c}\text { Протяженность } \\
\text { береговой } \\
\text { линии } \\
\text { Shore line } \\
\text { length }\end{array}$} & \multirow{2}{*}{ 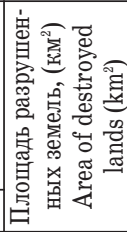 } \\
\hline & & $\mathrm{KM} / \mathrm{km}$ & $\%$ & \\
\hline $\begin{array}{l}\text { Умеренно-опасный, } \\
\text { опасный, особо опасный } \\
\text { (классификация } \\
\text { В.T. Трофимова) } \\
\text { Moderately dangerous, } \\
\text { dangerous, highly } \\
\text { dangerous (classification } \\
\text { of V.T. Trofimov) }\end{array}$ & от 1 до 4 & 190 & 30 & 10,5 \\
\hline $\begin{array}{l}\text { Катастрофический } \\
\text { Disastrous }\end{array}$ & от 4 до 8 & 120 & 19 & 18,5 \\
\hline
\end{tabular}




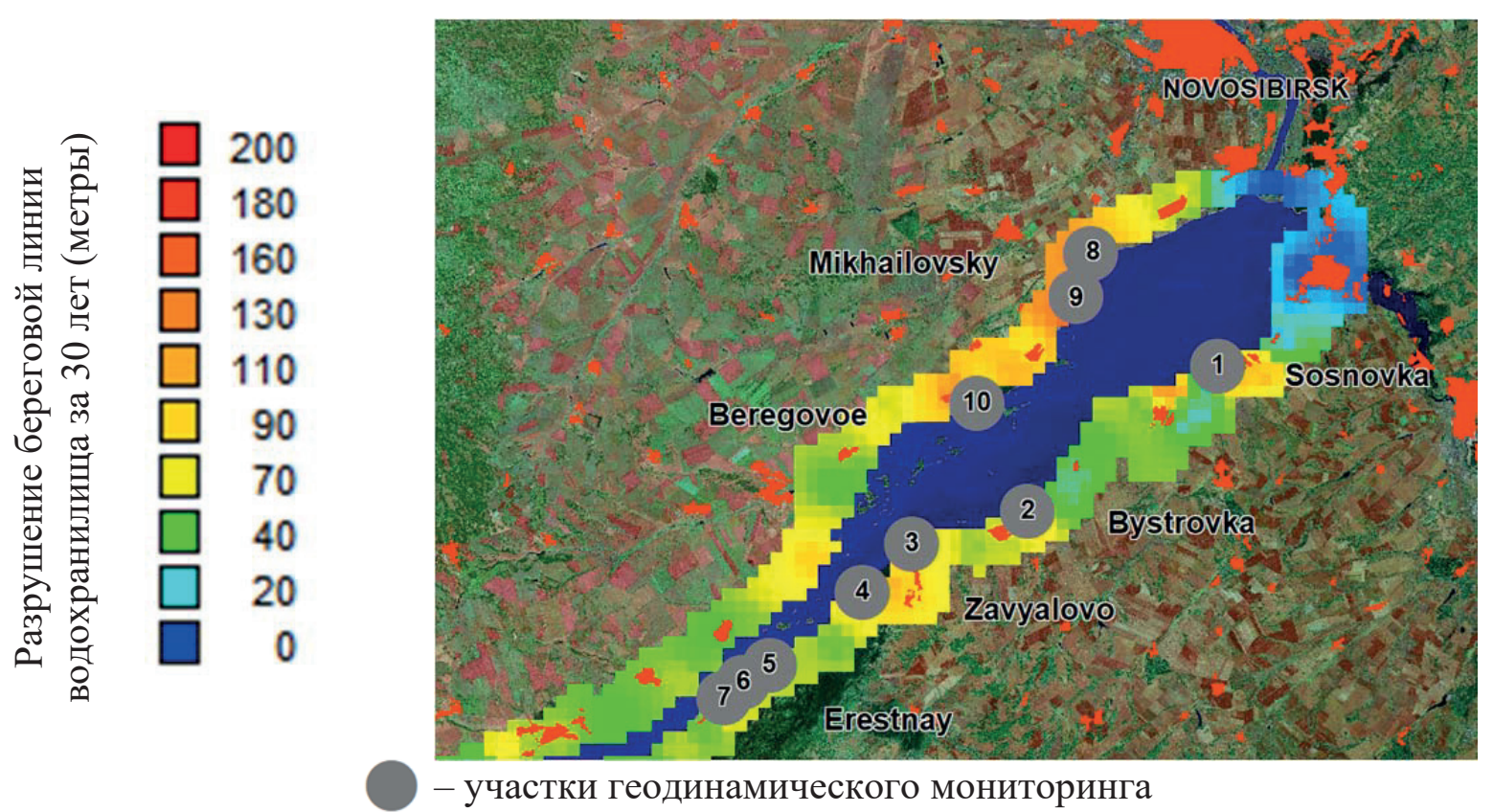

Рис. 7. Градиентная модель смещения береговой линии

Fig. 7. Gradient model of shore line shift

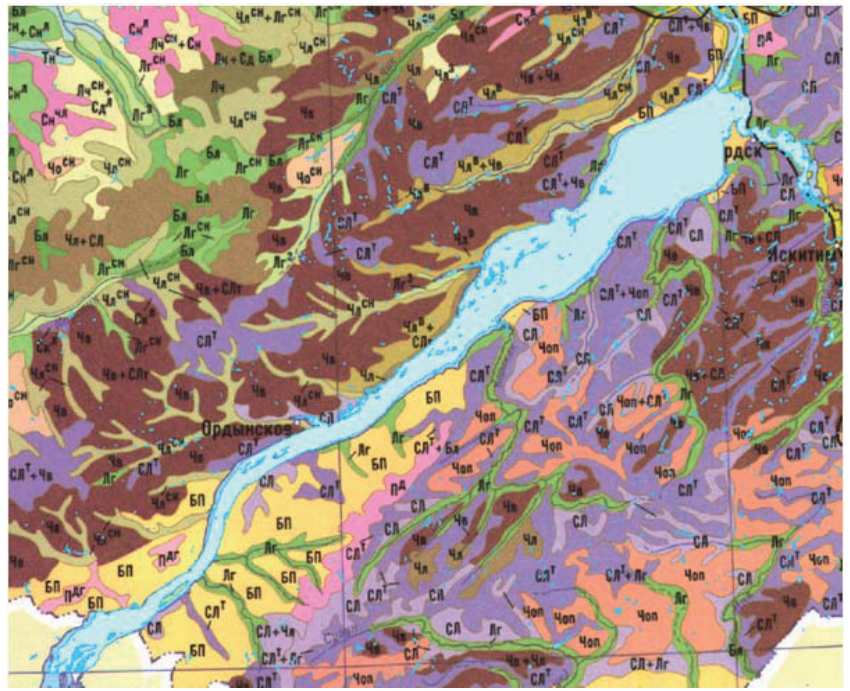

Условные обозначения типов почв

\begin{tabular}{|c|c|}
\hline Yon & - черноземы оподзоленные \\
\hline 5П & - боровые пески \\
\hline CAr & - серые лесные глеевые \\
\hline 48 & - черноземы выщелоченные \\
\hline Mr & - луговые \\
\hline $4 \pi$ & - лугово-черноземные \\
\hline CЛ & - серые лесные \\
\hline $\mathrm{N}_{4} \mathrm{CH}$ & - черноземы луговые солонцеваты \\
\hline
\end{tabular}

Pис. 8. Фрагмент почвенной карты

Fig. 8. Fragment of the soil map

Учитывая данные по типам почв и скоростям их разрушения за предыдущие периоды, можно определить скорости разрушения береговой линии в зависимости от почвообразующих пород. Например, наибольшая скорость берегоразрушения -5 м в год, установлена на земельных участках, почвообразующими породами которых являются боровые пески. Такие земельные участки занимают $61 \%$ от общей площади разрушаемой территории берега. Оставшиеся земельные участки заняты темно-серыми лесными, луговыми и лугово-черноземными почвами. Скорости разрушения данных типов почв не превышают 2 м в год.
Также определенный практический интерес представляет и прогноз скоростей разрушения береговой линии в зависимости от типов почв и определение земельных участков, которые в силу специфики почвенного состава наиболее пострадают в результате ветро-волновой эрозии. На территории прибрежной зоны Новосибирского водохранилища наиболее интенсивному разрушению подвергаются земельные участки, почвослогающие породы которых представляют собой боровые пески.

Для выполнения работ по картографированию нарушений почвенного и растительного покровов предлагается комплексное зонирование земель с 


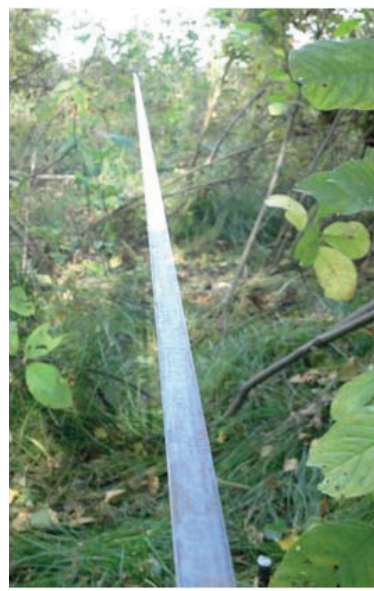

$a / a$

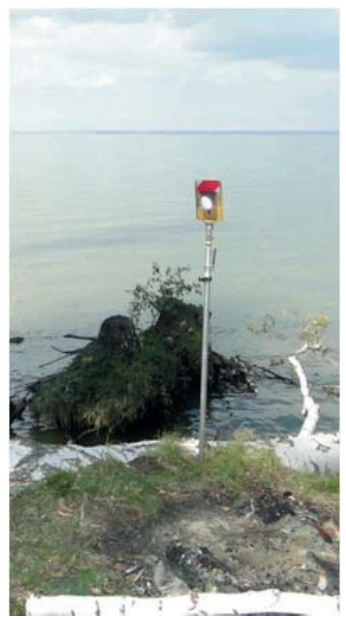

$\sigma / b$

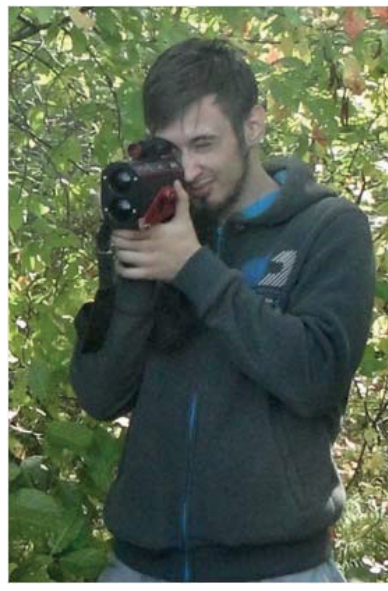

$B / c$

Pис.9. Геодезический мониторинг береговой линии: а) применение геодезической рулетки; б) выполнение геодезических излерений; в) излерение с использованием лазерной рулетки

Fig. 9. Examples of shore line monitoring with the use of geodetic instruments: a) geodetic tape measurement (up to 50 meters); $b$ ) reflector use for measuring; $c$ ) use of laser tape to determine the distance from basic direction to the shore line

учетом кадастрового деления, функционального использования и анализа сложившихся социально-экономических отношений. При этом перспективным является применение подхода к зонированию территории, изложенного в работе [16]. В частности, полученные при анализе нарушенности земель ареалы необходимо в дальнейшем оценивать не только по степени их антропогенной трансформации, но и по социально-экономической эффективности использования населением этих земельных участков [17].

Для организации системы наземного мониторинга были определены 10 участков береговой линии, на которых наблюдается максимальное по скорости берегоразрушение. Выбранные земельные участки отмечены номерами на рис. 7. На каждом участке было закреплено по три репера для проведения контрольных измерений положения береговой линии. От реперов проводились измерения до береговой линии (рис. 9).

Для организации системы современного мониторинга в качестве данных дистанционного зондирования целесообразно использовать материалы космической съёмки высокого разрешения в видимом диапазоне или съёмку с использованием беспилотных авиационных систем. Применение космической съёмки для мониторинга береговой линии может оказаться менее эффективным из-за сложной и сильно вытянутой формы съёмочного участка. В этом случае наиболее целесообразна организация системы мониторинга территории водохранилища с помощью применения технологии беспилотных авиационных систем. На участках, где береговая линия интенсивно разрушается, предлагается организовать не только систему топографического мониторинга, но и аэрофотосъемочные работы с применением беспилотных авиационных си- стем и специализированного программного обеспечения, в том числе позволяющего создать геопортал [18-23].

Аэрофотосъёмка должна выполняться минимум в два маршрута: первый маршрут над линией уреза воды, второй - над прилегающей береговой частью (для обеспечения планово-высотного съёмочного обоснования). Разрешение съёмки для обеспечения идентификации связующих и опорных точек составляет 5-10 см. Общая длина береговой линии Новосибирского водохранилища - более $600 \mathrm{kм}$, соответственно, длина съёмочных маршрутов - более 1200 км. В связи с этим для съёмки целесообразно использовать БПЛА самолётного типа из-за их более высокой производительности (до 500 км в день). Для дополнительного мониторинга тех участков, которые подвержены катастрофическому отступанию береговой линии (отдельные участки береговой линии суммарной длиной около $120 \mathrm{kм)} \mathrm{и} \mathrm{локального} \mathrm{объектного} \mathrm{мо-}$ ниторинга, целесообразно использовать квадрокоптеры. Планирование аэрофотосъёмки выполняется с использованием наземных станций управления БПЛА, например Mission Planner (рис. 10).

Результатом съемки является ортофотоплан прибрежной части водохранилища, по которому определяется текущее положение линии уреза воды с точностью до 10 см [13]. Полученные данные о состоянии береговой линии и прилегающих к водохранилищу земельных участков используются для расчета численных значений критериев эффективности землепользования. При этом возможно применение соответствующих подходов к ценообразованию при определении кадастровой стоимости земельных ресурсов рекреационной или лесной категории, занятых промышленными объектами, изложенных в работах $[4,5]$. 


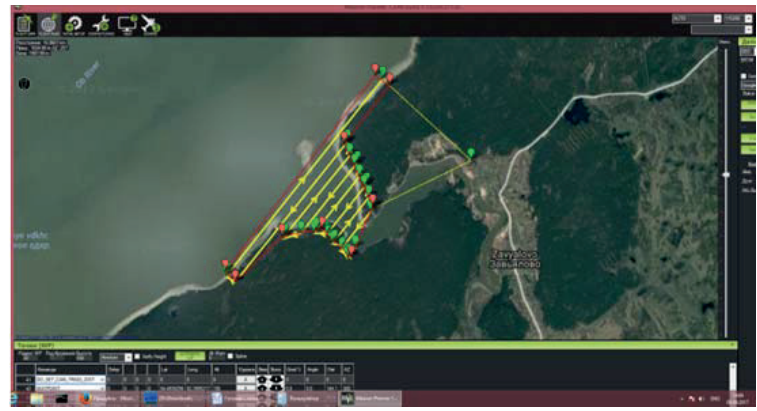

$a / a$

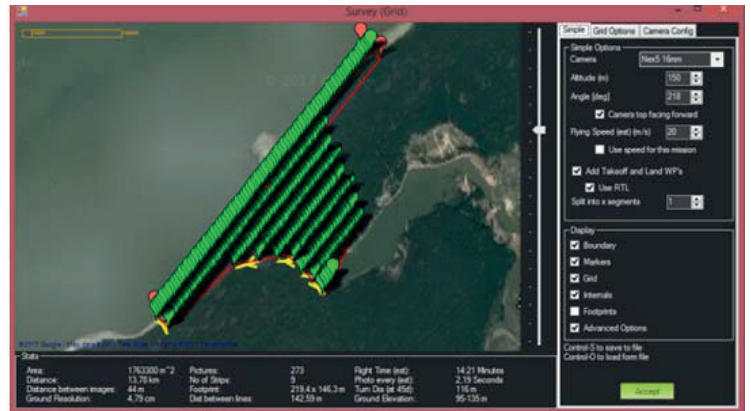

$\sigma / b$

Рис. 10. Пример планирования аэрофотосъёмочных работ с использованием станиии управления Міssion Planпег: а) общая схема аэрофотосъёмочных маршрутов; б) расчёт параметров аэрофотосъёмки

Fig. 10. Example of aerial survey works with the use of ground control station Mission Planner: a) general scheme of aerial survey routes; $b$ ) aerial survey parameters calculation

\section{Заключение}

Мониторинг состояния береговой линии водохранилища необходим в первую очередь для проверки адекватности прогнозной модели прогрессирования ветро-волновой эрозии. Выполненные исследования показали соответствие прогнозных и фактических значений разрушения береговой линии на 87 \% . В первую очередь расхождения были связаны с неверным определением типов почв и скоростей их разрушения. Также прогнозная модель требует уточнения в зависимости от водности рассматриваемого временного периода. В маловодные годы скорость разрушения береговой линии снижается на 25-40\% на различных участках водохранилища. Водность обусловлена запасами снега, в первую очередь на территории Алтая. Также динамика разрушения береговой линии меняется в зависимости от времени года: максимальные разрушения происходят в весенний период при максимальном уровне воды в водохранилище, постепенно интенсивность разрушения затухает и полностью прекращается зимой после формирования ледяного покрова.

Для решения задачи организации экономически-эффективного землепользования на прибрежной территории водохранилища наиболее рационально развивать рекреационное землепользование. Для исследуемой территории Правительством Новосибирской области совместно с широким кругом специалистов в области территориального планирования, кадастра, земельных ресурсов, а также министерства здравоохранения разработаны планы по развитию рекреационного направления природопользования. В частности, наряду с существующей инфраструктурой рекреационно-оздоровительных объектов планируется создание двух крупных рекреационных зон для обеспечения населения города Новосибирска и близлежащих населенных пунктов объектами природного лечебновосстановительного значения. Реализация проектов намечена на период с 2018 по 2025 гг. Прогнозируется существенный экономический эффект, выражающийся в увеличении доходов от использования прибрежной территории водохранилища на $40 \%$. Главным элементом создания современных основ рационального и экономически эффективного землепользования является переход на цифровую экономику с применением геотехнологий [24]. Также при строительстве объектов туристической и рекреационно-оздоровительной инфраструктуры намечено проведение работ по берегоукреплению, общим объемом свыше 20 км. Проведение данных работ позволит увеличить общий срок эксплуатации водохранилища и существенно улучшить качество воды.

\section{Теоретическая и практическая значимость исследования}

Предлагаемая технологическая схема геоинформационного мониторинга является эффективной с позиции временных и финансовых затрат, обеспечивает оперативный контроль состояния береговой линии, позволяет оценить качество выполненных берегоукрепительных работ.

Выявлены участки береговой линии с особо опасным и катастрофическим разрушением. Для них определена технология мониторинга и периодичность наблюдений. Реализация разработанной программы комплексного экологически ориентированного рационального землепользования на территории водохранилищ позволит не только решить проблему с обеспечением населения прилегающих территорий запасами питьевой воды, но и с максимальной экономической выгодой использовать прибрежные территории в рекреационной сфере.

Исследования проводились при финансовой поддержке Правительства Новосибирской области и выделенного гранта: "Исследование ветро-волновой эрозии береговой линии Новосибирского водохранилища». Авторы выражают благодарность руководству Новосибирской области за проявленный интерес к их исследованиям и финансирование мероприятий по исследованию состояния береговой линии Новосибирского водохранилища. 


\section{СПИСОК ЛИТЕРАТУРЫ}

1. Верхотуров Д. Во глубине сибирских гидроэлектростанций // Красноярская региональная общественная экологическая организация «Плотина»: сборник статей. - Красноярск: КРОЭО «Плотина», 2009. - $91 \mathrm{c.}$

2. Бейром С.Г., Вострякова Н.В. Изменение природных условий в средней Оби после создания Новосибирской гидроэлектростанции. - Новосибирск: Наука, Сибирское Отделение, 1973. $250 \mathrm{c.}$

3. Комплексные исследования Новосибирского водохранилища / Труды Сибирского регионального научно-исследовательского гидрометеорологического института / под ред. Ю.И. Подлипского, Т.С. Чайковской. - М.: Гидрометеоиздат, 1985. Вып. 70. -135 c.

4. Sibly H. Pricing and Management of Recreational Activities which Use Natural Resources // Environmental and Resource Economics. - 2001. - № 18. - P. 339-354. URL: https://link. springer.com/article/10.1023/A:1011165132180 (дата обращения 10.11.2019).

5. Pak M., Türker M.F. Determination of forest recreational use value of forest resources in Turkey: Sazalan forest recreation site sample. URL: http://www.fao.org/docrep/ARTICLE/WFC/XII/ 0411-A1.HTM (дата обращения 10.11.2019).

6. Oulidi H.J., Moumen A. Towards a Spatial Data Infrastucture and an Integrated Management of Groundwater Recourses // Journal of Geographic Information Systems. - 2015. - № 7. P. 667-676.

7. Elements of Geoinformation Support of Natural Resource Management System / A.V. Dubrovsky, I.T. Antipov, A.I. Kalenitsky, A.P. Guk // International Journal of Advanced Biotechnology and Research (IJBR). - 2018. - V. 9. - Iss. 1. - P. 1185-1202.

8. Об утверждении концепции развития отрасли геодезия и картографии до 2020 г.: утверждена Распоряжением Правительства Российской Федерации от 17 декабря 2010 г. № 2378-р. URL: http://economy.gov.ru/minec/activity/sections/landrelations/geodesyandcartography/doc20101217_01 (дата обращения 10.11.2019).

9. Седельников В.П. Космический сегмент в структуре Системы государственного топографического мониторинга // Геоматика № 2. - М.: Совзонд, 2012. - С. 57-60.

10. Горбунов А.В., Ильина И.Ю., Саульский В.К. Состояние и перспективы развития космических комплексов «Канопус-В» и «Метеор-М» // Ракетно-космическое приборостроение и информационные системы. - 2015. - Т. 2. - № 4. - С. 14-19.

11. Фарутин И.Н., Федоткин Д.И. Технологические решения компании Сканэкс для приема и обработки спутниковой информации // Сборник статей по материалам международного научного конгресса «Интерэкспо Гео-Сибирь», 2011. - Новосибирск: Сибирская государственная геодезическая академия, 2011. C. $167-169$.

12. Иноземцев Д.П. Автоматизированная аэрофотосъёмка с помощью программно-аппаратного комплекса «GeoScan-PhotoScan» // САПР и ГИС автомобильных дорог. - 2014. - № 1 (2). C. $46-51$.
13. Lucas G., Lenart Cs., Solymosi J. Development and testing of geoprocessing models for the automatic generation of remediation plan and navigation data to use in industrial disaster remediation // Open Geospatial Data, Software and Standards. - 2016. № 1:5. URL: https://opengeospatialdata.springeropen.com/articles/10.1186/s40965-016-0006-z (дата обращения 10.11.2019).

14. Гридэл Т.Е., Алленби Б.Р. Промышленная экология. - М.: Юнити-Дана, 2012. - 527 с.

15. Трофимов В.Т., Вознесенский Е.А., Королев В.А. Инженерная геология России. Т. 1. Грунты России. - М.: КДУ, 2011. $671 \mathrm{c.}$

16. Дубровский А.В. Возможности применения геоинформационного анализа в решении задач мониторинга и моделирования пространственных структур // Известия вузов. Геодезия и аэрофотосъемка. - 2015. - № 5/С. - С. 220-224.

17. Joseph M., Moeckel R. Automated design of gradual zone systems // Open Geospatial Data, Software and Standards. - 2017, Springer Open. URL: https://doi.org/10.1186/s40965-017-0032-5 (дата обращения 10.11.2019).

18. Карпик, А. П. Методологические и технологические основы геоинформационного обеспечения территорий. - Новосибирск: Сибирская государственная геодезическая академия, 2004. $250 \mathrm{c}$.

19. Геопространственный дискурс в системе опережающего научного мышления / А.П. Карпик, Д.В. Лисицкий, К.С. Байков, А.Г. Осипов, В.Н. Савиных // Вестник Сибирского государственного университета геосистем и технологий. - 2017. T. 22. - № 4. - C. 53-67.

20. Bakillah M., Liang S. Open geospatial data, software and standards 0pen Geospatial Data // Software and Standards. - 2016. № 1:1. URL: https://opengeospatialdata.springeropen.com/articles/10.1186/s40965-016-0004-1 (дата обращения 10.11.2019).

21. Becirspahic L., Karabegovic A. Web portals for visualizing and searching spatial data // Information and Communication Technology, Electronics and Microelectronics (MIPR0), 2015. $38^{\text {th }}$ International Convention on. - Opatija, Croatia, 2015. P. $305-311$.

22. Steiniger S., Hunter A.J.S. Free and open source GIS software for building a spatial data infrastructure // Geospatial Free and Open Source Software in the $21^{\text {st }}$ Century. LNGC. - Heidelberg: Springer, 2012. - P. 247-261.

23. A Web Map Service implementation for the visualization of multidimensional gridded environmental data / J.D. Blower, A.L. Gemmell, G.H. Griffiths, K. Haines, A. Santokhee, X. Yang // Environmental Modelling \& Software. - September 2013. - V. 47. - P. 218-224.

24. Digital economy and geoinformation technologies / D. Lisitsky, K. Baykov, A. Osipov, A. Grishanova, V. Savinykh // Actual Issues of Mechanical Engineering: International Conference, 2017. - Tomsk, Russia, 27-29 July, 2017. DOI: 10.2991/aime-17.2017.120.

Поступила: 12.11 .2018 г. 


\section{Информация об авторах}

Карпик А.П., доктор технических наук, профессор, ректор Сибирского государственного университета геосистем и технологий.

Аврунев Е.И., кандидат технических наук, доцент кафедры кадастра и территориального планирования Сибирского государственного университета геосистем и технологий.

Добротворская Н.И., доктор сельскохозяйственных наук, профессор кафедры кадастра и территориального планирования Сибирского государственного университета геосистем и технологий.

Дубровский A.B., кандидат технических наук, заведующий кафедрой кадастра и территориального планирования, заведующий научно-производственным центром «Дигитайзер» Сибирского государственного университета геосистем и технологий.

Малыгина О.И., кандидат технических наук, доцент кафедры кадастра и территориального планирования Сибирского государственного университета геосистем и технологий.

Попов В.K. , доктор геолого-минералогических наук, профессор кафедры гидрогеологии, инженерной геологии и землеустройства Инженерной школы природных ресурсов Национального исследовательского Томского политехнического университета. 
UDC 528.004

\title{
ORGANIZATION OF THE SYSTEM OF GEOINFORMATION MONITORING THE LAND RESOURCES IN NOVOSIBIRSK BASIN SHORE ZONE
}

Alexandr P. Karpik', rektorat@ssga.ru

Evgeny l. Avrunev', avrynev_ei@ngs.ru

Nadezhda I. Dobrotvorskaya', dobrotvorskaya@mail.ru

\section{Alexey V. Dubrovsky',} avd5@mail.ru

\section{Olesya I. Malygina',} 131379@mail.ru

\author{
Viktor K. Popov $^{2}$ \\ ${ }^{1}$ Siberian State University of Geosystems and Technologies, \\ 10, Plakhotny street, Novosibirsk, 630108, Russia. \\ ${ }^{2}$ National Research Tomsk Polytechnic University, \\ 30, Lenin avenue, Tomsk, 634050, Russia.
}

Relevance of the research is caused by the fact that modern organization of infrastructure objects, industrial and economical complexes must be secure, ecologically and economically efficient. The article states the problem of system organization in rational use and control for water reservoir conditions applying geotechnologies and Earth's remote sensing systems. The territory of the Novosibirsk Basin (Russia, the Novosibirsk region) is considered as the object of the research. On the territory under investigation there is the deterioration of ecological situation as a result of wind-and-wave erosion of shore lines and intensive wash-out of soils, vegetation, trees and chemical agricultural fertilizers etc. into the water. The article substantiates the introduction of the term - technogenic natural territorial complexes. The Earth's remote sensing data define soil erosion velocities along the whole length of the water basin shore line. On the basis of the research we made a forecast model of shore line destruction. The spots of geodynamic monitoring are settled and the observation frequency is determined. The authors drawn the conclusions on the necessity of shore line stabilization, as well as more intensive involvement of the water basin territory into recreational activity.

The aim of the research is to develop the geoinformation system for monitoring land resources of basin shore zone, on the example of the Novosibirsk water basin territory.

Objects: land resources of the Novosibirsk water basin shore zone.

Methods. When solving the tasks we used both general research methods (system analysis, synthesis, observation, comparison, measurement, generalization), and special research methods (monitoring of environment and land conditions with the use of Earth's remote sensing data, digital cartography method and geoinformational analysis and modelling).

Results. The authors developed technological scheme of geoinformational monitoring the system organization for technogenic natural territorial complex - water basin. The authors built the forecast gradient model of water basin shore line displacement velocities. On the basis of the analysis of this model the authors determined the list of real estate objects which will be destroyed in the result of wind-andwave erosion development.

\section{Key words:}

Satellites monitoring methods, technogenic natural territorial complexes, land resources, unmanned aerial vehicles, digital economy, water objects.

The research was financially supported by the Administration of Novosibirsk region and the grant «Study of wind-wave erosion of the shore line of Novosibirsk basin shore zone».

The authors appreciate the interest of the Administration of Novosibirsk region in the research and funding the investigations of the shore line state in Novosibirsk basin shore zone.

\section{REFERENCES}

1. Verkhoturov D. Vo glubine sibirskikh gidroelektrostantsii [In the deep of Siberian PS]. Krasnoyarskaya regionalnaya obshchestvennaya ekologicheskaya organizatsija «Plotina»: sbornik statey [Krasnoyarsk regional public ecological organization «Plotina»: collection of articles]. Krasnoyarsk, KRPEO Publ., 2009. 91 p.
2. Beyrom S.G., Vostryakova N.V. Izmenenie prirodnykh usloviy $v$ sredney Obi posle sozdaniya Novosibirskoy gidroelektrostantsii [Changing of natural conditions in central $0 \mathrm{~b}$ after creation of Novosibirsk Power Station]. Novosibirsk, Nauka, Publ., 1973. 250 p.

3. Kompleksnye issledovaniya Novosibirskogo vodokhranilishcha [Complex research of the Novosibirsk water basin]. Kompleksnye 
issledovaniya Novosibirskogo vodokhranilishcha [Proceedings of the Siberian Regional Research Hydrometeorological Institute]. Eds. I.Yu. Podlipsky, T.S. Tchaikovskaya. Moscow, Gidrometeoizdat Publ., 1985. Iss. 70, 135 p.

4. Sibly H. Pricing and Management of Recreational Activities Which Use Natural Resources. Environmental and Resource Economics, 2001, no. 18, pp. 339-354. Available at: https://link.springer.com/article/10.1023/A:1011165132180 (accessed 12 May 2019).

5. Pak M., Türker M.F. Determination of forest recreational use value of forest resources in Turkey: Sazalan forest recreation site sample. Available at: http://www.fao.org/docrep/ARTICLE/WFC/XII/0411-A1.HTM (accessed 12 May 2019).

6. Oulidi H.J., Moumen A. Towards a Spatial Data Infrastucture and an Integrated Management of Groundwater Recourses. Journal of Geographic Information Systems, 2015, no. 7, pp. 667-676.

7. Dubrovsky A.V., Antipov I.T., Kalenitsky A.I., Guk A.P. Elements of Geoinformation Support of Natural Resource Management System. International Journal of Advanced Biotechnology and Research (IJBR), 2018, vol. 9, Iss. 1, pp. 1185-1202.

8. Ob utverzhdenii kontseptsii razvitiya otrasli geodeziya i kartografii do 2020 g.: utverzhdena Rasporyazheniem Pravitelstva Rossiyskoy Federatsii ot 17 dekabrya $2010 \mathrm{~g}$. № 2378-r [The concept of branch development "Geodesy and Cartography» up to 2020, approved by the Government of the Russia Federation, December, 17, 2010 № 2378-r]. Available at: http://economy.gov.ru/minec/activity/sections/landrelations/geodesyandcartography/ doc201 01217_01 (accessed 12 May 2019).

9. Sedelnikov V.P. Kosmicheskiy segment v strukture Sistemy gosudarstvennogo topograficheskogo monitoringa [Space segment in the structure of State topographic monitoring system]. Geomatika № 2. Moscow, Sovzond Publ., 2012. pp. 57-60.

10. Gorbunov A.V., Ilina I.Yu., Saulskiy V.K. Condition and perspectives of development of space complexes «Kanopus-V» and «Meteor-M». Space missile instrument making and information systems, 2015, vol. 2, no. 4, pp. 14-19. In Rus.

11. Farutin I.N., Fedotkin D.I. Tekhnologicheskie resheniya kompanii Skanyeks dlya priema i obrabotki sputnikovoy informatsii [Technological solutions of Scanecs company for receiving and processing satellite information]. Sbornik statey po materialam mezhdunarodnogo nauchnogo kongressa «Interiekspo Geo-Sibir» [Collected papers of international scientific congress «InterExpo Geo-Siberia»]. Novosibirsk, Siberian State Geodetic Academy Publ., 2011. pp. 167-169.

12. Inozemtsev D.P. Avtomatizirovannaya aerofotosemka s pomoshchyu programmno-apparatnogo kompleksa «GeoScan-PhotoScan» [Automated aerial survey with the help of software and hardware complexes "GeoScan-PhotoScan»]. SAPR i GIS avtomobilnykh dorog, 2014, no. 1 (2), pp. 46-51.

13. Lucas G., Lenart Cs., Solymosi J. Development and testing of geoprocessing models for the automatic generation of remediation plan and navigation data to use in industrial disaster remediation. Open Geospatial Data, Software and Standards, 2016, no. 1:5. Available at: https://opengeospatialdata.springeropen.com/articles/10.1186/s40965-016-0006-z (accessed 12 May 2019).

14. Gridjel T.E., Allenbi B.R. Promyshlennaya ekologiya [Industrial ecology]. Moscow, Juniti-Dana Publ., 2012. 527 p.

15. Trofimov V.T., Voznesensky E.A., Korolev V.A. Inzhenernaya geologiya Rossii. T. 1. Grunty Rossii [Engineering Geology of Russia. Vol. 1. Soils of Russia]. Moscow, BHU Publ., 2011. 672 p.

16. Dubrovskiy A.V. Opportunities of geoinformational analysis implication for solving tasks of monitoring and modelling spatial structures. News of Higher Education, Geodesy and aerial survey, 2015, no. 5/P, pp. 220-224. In Rus.

17. Joseph M., Moeckel R. Automated design of gradual zone systems. Open Geospatial Data, Software and Standards, 2017, Springer Open. Available at: https://doi.org/10.1186/ s40965-017-0032-5 (accessed 12 May 2019).

18. Karpik A.P. Metodologicheskie i tekhnologicheskie osnovy geoinformatsionnogo obespecheniya territoriy [Methodological and technological basis of geoinformational territorial support]. Novosibirsk, Siberian State Geodetic Academy Publ., 2004. 250 p.

19. Karpik A.P., Lisitskiy D.V., Baykov K.S., Osipov A.G., Savinykh V.N. Geospatial discourse in the system of advanced scientific thinking. Siberian State University of Geosystems and Technologies Bulletin, 2017, vol. 22, no. 4, pp. 53-67. In Rus.

20. Bakillah M., Liang S. Open geospatial data, software and standards Open Geospatial Data. Software and Standards, 2016, no. 1:1. Available at: https://opengeospatialdata.springeropen.com/articles/10.1186/s40965-016-0004-1 (accessed 12 May 2019).

21. Becirspahic L., Karabegovic A. Web portals for visualizing and searching spatial data. Information and Communication Techno$\log y$, Electronics and Microelectronics (MIPRO), 2015. $38^{\text {th }} \mathrm{In}-$ ternational Convention on. Opatija, Croatia. 2015. pp. 305-311.

22. Steiniger S., Hunter A.J.S. Free and open source GIS software for building a spatial data infrastructure. Geospatial Free and Open Source Software in the $21^{\text {st }}$ Century. LNGC. Heidelberg, Springer, 2012. pp. 247-261.

23. Blower J.D., Gemmell A.L., Griffiths G.H., Haines K., Santokhee A., Yang X. A Web Map Service implementation for the visualization of multidimensional gridded environmental data. Environmental Modelling \& Software, September 2013, vol. 47, pp. 218-224.

24. Lisitsky D., Baykov K., Osipov A., Grishanova A., Savinykh V. Digital economy and geoinformation technologies. International Conference. Actual Issues of Mechanical Engineering. Tomsk Polytechnic University, Tomsk, Russia on 27-29 July, 2017. DOI: 10.2991/aime -17.2017.120.

Received: 12 November 2018.

\section{Information about the authors}

Alexandr P. Karpik, Dr. Sc., professor, rector, Siberian State University of Geosystems and Technologies.

Evgeny I. Avrunev, Cand. Sc., associate professor, Siberian State University of Geosystems and Technologies.

Nadezhda I. Dobrotvorskaya, Dr. Sc., professor, Siberian State University of Geosystems and Technologies.

Alexey V. Dubrovsky, Cand. Sc., head of the department, Siberian State University of Geosystems and Technologies.

Olesya I. Malygina, Cand. Sc., associate professor, Siberian State University of Geosystems and Technologies.

Viktor K. Popov, Dr. Sc., professor, National Research Tomsk Polytechnic University. 